\title{
An Investigation of the Relationship between Bacillus cereus, Bacillus thuringiensis and Bacillus mycoides using Pyrolysis Gas-Liquid Chromatography
}

\author{
By A. G. O'DONNELL, ${ }^{\dagger} \dagger$ H. J. H. MACFIE AND J. R. NORRIS : \\ Agricultural Research Council, Meat Research Institute, Langford, Bristol BS18 7DY
}

(Received 29 January 1980)

\begin{abstract}
Nine strains of Bacillus mycoides, 10 of Bacillus cereus and 18 of Bacillus thuringiensis were analysed using pyrolysis gas-liquid chromatography. Application of canonical variates analysis to the resultant pyrograms showed that these organisms formed three distinct groups. Stepwise discriminant analysis with jacknifing showed that of the original 27 peak heights used to define the canonical variates axes, only two were needed to obtain reasonably stable discriminant functions. These discriminant functions (Dixon, 1975) are potentially valuable in identification. Jacknifing also indicated that, had it been an unknown, one strain of $B$. mycoides would have been incorrectly identified as $B$. cereus.
\end{abstract}

\section{INTRODUCTION}

Oxborrow et al. $(1976,1977 a, b)$ have shown that characterization of Bacillus species by pyrolysis gas-liquid chromatography (p.g.l.c.) is possible provided chromatographic conditions and major growth parameters remain constant. Changes in the physiological state of the samples, such as sporulation or pigmentation, result in marked changes in the pyrograms thereby making careful standardization of samples the most exacting requirement in applying p.g.l.c. to Bacillus characterization (O'Donnell \& Norris, 1980).

The complexity of the bacterial pyrogram requires the application of statistical methods to ensure a truly objective analysis (Stack et al., 1977; MacFie et al., 1978; MacFie \& Gutteridge, 1978; O'Donnell, 1978; O'Donnell et al., 1980; O’Donnell \& Norris, 1980) and visual comparison of pyrograms (Oxborrow et al., 1977a, b; Reiner \& Bayer, 1978) should no longer be considered acceptable for data analysis.

The present study, using three closely related but recognizably distinct groups of bacteria, was undertaken to explore the application of different statistical methods to the analysis of p.g.l.c. data.

\section{METHODS}

Organisms. The strains used are listed in Table 1. Those from the collection of the late Dr T. Gibson are now held on soil extract agar slopes at Newcastle University. Other strains were received from the Deutsche Sammlung für Mikroorganismen and from Dr H. D. Burges, Glasshouse Crops Research Institute, Littlehampton. Organisms were grown on membrane filters (HAWP 047, $0.45 \mu \mathrm{m}$, Millipore) as described by Oxborrow et al. (1976). Each culture was incubated for $5 \mathrm{~d}$ at $30^{\circ} \mathrm{C}$ on nutrient agar (Oxoid) until well sporulated.

Sample preparation. Samples were harvested from the membrane using a sterile platinum loop and stored in sterile distilled water at $-4{ }^{\circ} \mathrm{C}$ prior to analysis. Bacterial suspensions, containing 80 to $100 \mu \mathrm{g}$ (dry wt)

† Present address: Department of Chemistry, University of Newcastle, Newcastle-upon-Tyne NE1 7RU.

¥ Present address: Cadbury Schweppes Ltd, Group Research, c/o Department of Chemistry, University of Reading, Reading RG6 2AD. 


\title{
Table 1. Organisms used
}

Strain no.

\author{
Identity and origin
}

$1-18$

$19-27$

\author{
Bacillus thuringiensis: from H. D. Burges
}

28-37 Bacillus mycoides: 19, DSM 299; 20-25, Gibson nos 677, 681, 932, 690, 15, 680; 26 and 27, DSM 303 and 307

Bacillus cereus: 28, DSM 31 (neotype); 29-37, Gibson nos 479, 1110, 704, 467, 905, 669, $850,1103,670$

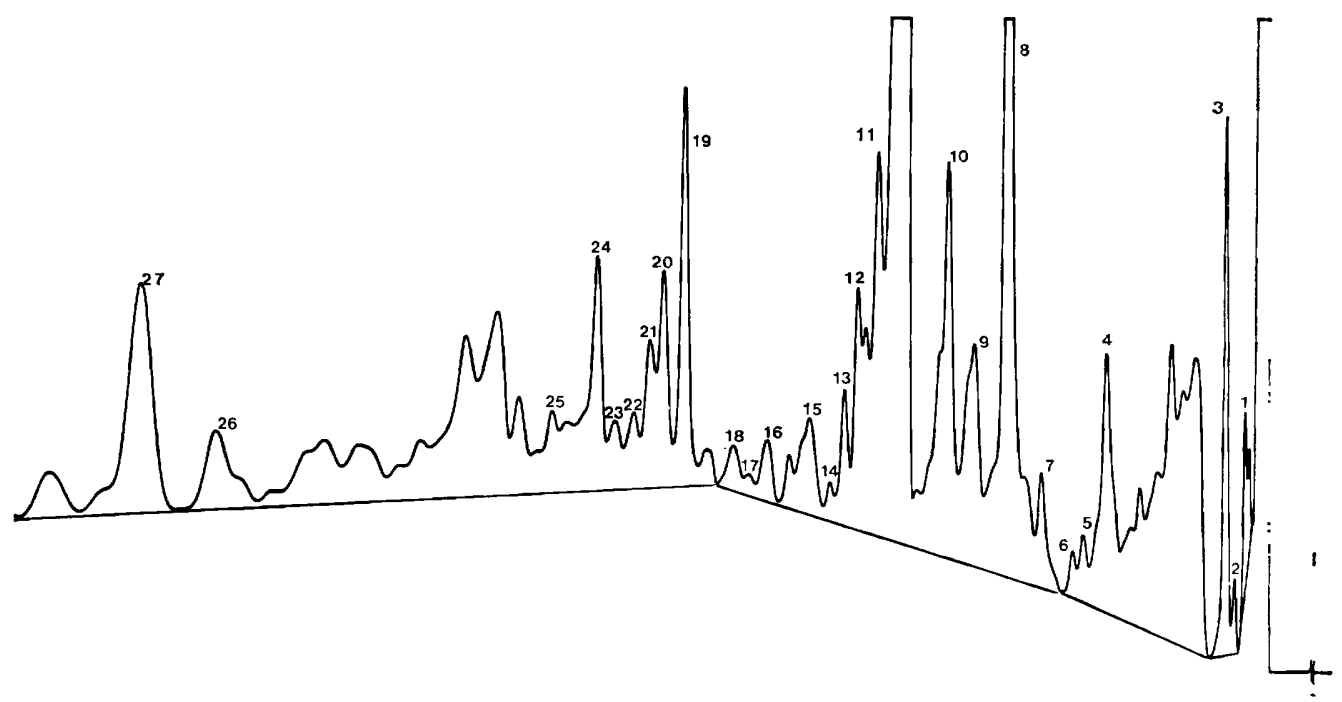

Fig. 1. Pyrogram of $B$. thuringiensis no. 1 showing the baseline and chosen set of peaks.

cells, were applied directly to Curie-point wires (O’Donnell \& Norris, 1980) and allowed to dry at ambient temperature in a laminar flow cabinet.

Chromatography. Chromatographic analysis used a Pye Unicam 204 gas chromatograph fitted with $2.6 \mathrm{~m} \times 5 \mathrm{~mm}$ (i.d.) dual columns, packed with $5 \%(\mathrm{w} / \mathrm{w})$ Carbowax 20M-TPA on Chromosorb G, 80 to 100 mesh, AW-DMCS (Phase Separations Ltd, Queensferry, Clwyd). Pyrolysis was carried out in a stream of nitrogen $\left(20 \mathrm{ml} \mathrm{min}^{-1}\right)$ at $610^{\circ} \mathrm{C}$ for $4 \mathrm{~s}$ using a commercially available pyrolyser (Pye Unicam) compatible with the 204 series gas chromatograph. An injection temperature of $250^{\circ} \mathrm{C}$ was used. Following an initial hold at $75^{\circ} \mathrm{C}$ for $2 \mathrm{~min}$, the oven temperature was increased at $8{ }^{\circ} \mathrm{C} \mathrm{min}^{-1}$ to $200^{\circ} \mathrm{C}$ and held at that temperature. Raising the temperature to $230^{\circ} \mathrm{C}$ after an analysis removed the compounds of higher boiling point thereby cleaning the column. The total analysis time was approximately $50 \mathrm{~min}$. The output from the column was detected using a flame ionization detector at an attenuation of 128 and recorded at $1 \mathrm{~cm} \mathrm{~min} \mathbf{m}^{-1}$ simultaneously on two chart recorders set at $10 \mathrm{mV}$ and $50 \mathrm{mV}$ full-scale defiection, respectively.

Data collection. Each culture was plated in duplicate and suspensions prepared from each plate were analysed twice. Peak heights, the variables in the statistical analyses, were measured relative to a baseline (Fig. 1). The shape of the baseline used was dependent upon the shape of the pyrogram and was set so that all of the chosen peaks could be measured easily. Although setting a baseline was an arbitrary procedure, once established for a particular study it was set to all the pyrograms in the same way. To eliminate differences between pyrograms due to variations in sample size, a standardization procedure was used in which each peak involved in the analysis was divided by the sum of the chosen set of peaks and the resultant quotient multiplied by 1000 . In this way each of the selected peak heights was represented as a fraction of the sum of chosen peaks and pyrograms of different sample size could be compared. For the purposes of the statistical methods the analyses representative of each strain were averaged.

Data analysis. In analysing the data the following three questions were asked: (1) Did the complete data indicate consistent differences between the species of bacteria? (2) What was the minimum number of peaks required to achieve $100 \%$ discrimination and what peaks made up this subset? (3) How successfully can this identification procedure be expected to allocate unknown organisms?

The statistical methods used are listed in order below.

(i) Canonical variates. The application of this technique to p.g.l.c. data has been discussed elsewhere 


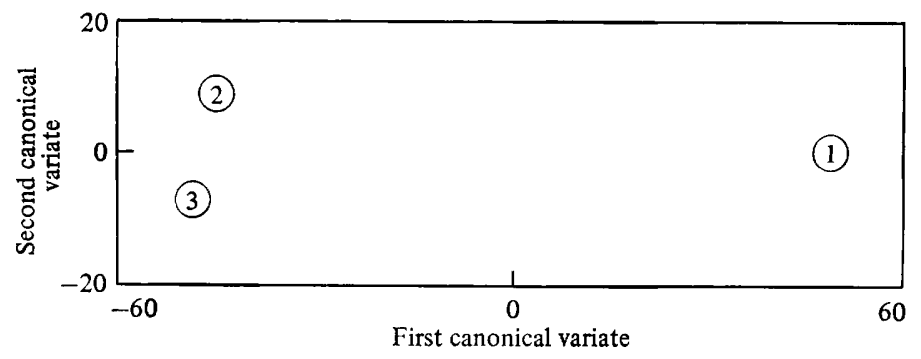

Fig. 2. Plot of species means relative to the first two canonical variate axes. (1) Mean of 18 strains of B. thuringiensis. (2) Mean of 9 strains of B. mycoides. (3) Mean of 10 strains of B. cereus. All 27 peak heights have been used. Circles define $95 \%$ confidence regions for each species.

(MacFie et al., 1978; MacFie \& Gutteridge, 1978; O’Donnell, 1978; O'Donnell et al., 1980; O'Donnell \& Norris, 1980).

(ii) Stepwise discriminant analysis. This is an iterative technique that enables the experimenter to obtain the best discrimination among species using the minimum number of peaks. At the first step, that peak is selected for which the ratio of the variation between the species to the average variation within the species is a maximum ( $F$ ratio). A second peak is included such that the multivariate generalization of the $F$ ratio (Wilks Lambda) is maximized. This procedure is repeated until either all the peaks have been included or addition (or subtraction) of any of the remaining peaks does not increase the Wilks Lambda criterion. At each stage an approximate $F$ value, which tests the significance of the improvement in discrimination, is determined and indicated. In addition, the generalized Mahalanobis distances (Mahalanobis, 1936) of each sample from each of the specics means are calculated. Alternatively discriminant functions can be calculated, which are linear combinations of the peaks, one for each species such that the discriminant scores will have the opposite ranking to the corresponding Mahalanobis distances. Thus a sample would be 'allocated' to the species for which it achieves the highest discriminant score.

(iii) Jacknifing or 'leaving one out' procedure. This procedure, developed by Lachenbruch \& Mickey (1968), is used at each step of the stepwise discriminant analysis to test the stability of the discriminant functions obtained. Each sample is removed in turn from the analysis and the discriminant functions are recomputed. The sample is then reallocated to that species for which its discriminant score is a maximum (equivalent to minimum Mahalanobis distance). Comparison of the percentage of correct allocations before and after jacknifing gives an estimate of stability. Lachenbruch \& Mickey (1968) report that the error rate after jacknifing is an unbiased estimate of the actual error rate in discriminating between the whole populations of the groups (question 3 above).

The stepwise discriminant and jacknifing programs are available in the BMDP statistical computing package (Dixon, 1975) and were run on an ICL System 4 computer at the University of Wales Institute of Science and Technology, Cardiff.

\section{RESULTS AND DISCUSSION}

The result of applying canonical variates analysis to the pyrograms is shown in Fig. 2. This plot represents $100 \%$ of the total generalized variation between groups and shows that pyrograms of $B$. cereus, $B$. mycoides and $B$. thuringiensis are consistently different and allow separation into three distinct groups. For this set of data the relative positions of the species suggested that $B$. cereus and $B$. mycoides are more closely related to one another than to B. thuringiensis.

Figure 3 summarizes the results of applying stepwise discriminant analysis, with jacknifing, to these data. The order of peak inclusion is given along the baseline. After just two peaks (19 and 10) had been included, only strain 26 was not correctly reallocated after jacknifing. All strains were correctly allocated (before jacknifing) after nine peaks had been included, and with 13 peaks included all strains were also correctly reallocated after being jacknifed. As more peaks were included the number of strains correctly reallocated fluctuated and dropped to 35 out of 37 .

Figure 3 succinctly expresses the practical problems in selecting the most stable subset for 


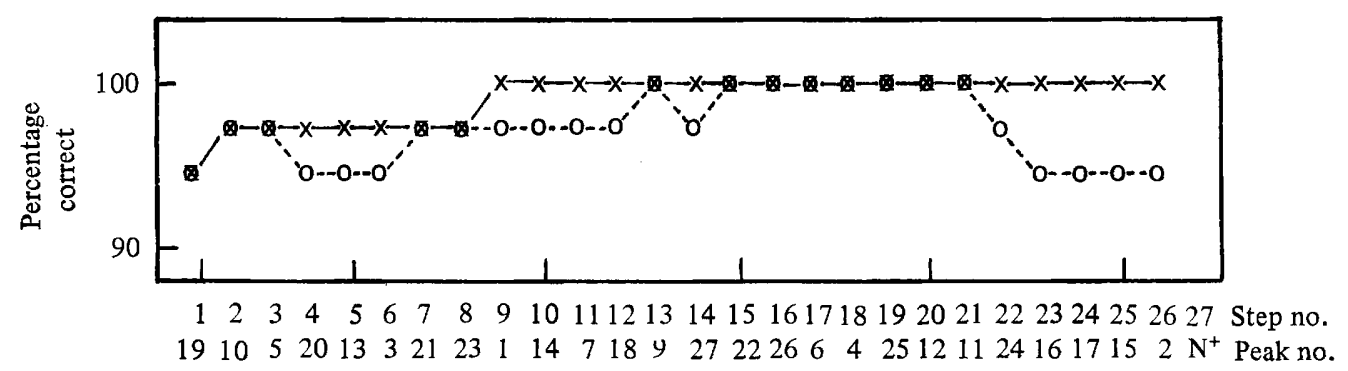

Fig. 3. Plot of percentage correctly jacknifed $(x)$ and percentage correctly discriminated $(O)$ against peak number for the $B$. cereus, $B$. mycoides, $B$. thuringiensis study. $\mathrm{N}^{+}=$Peak 8 not entered, because no extra discrimination was achieved.

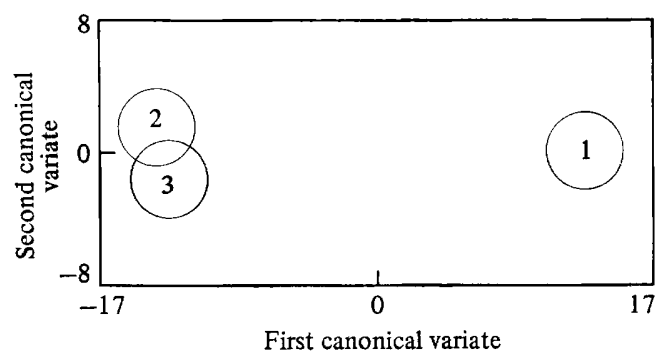

Fig. 4. Plot of species means relative to the first two canonical variate axes. (1) Mean of 18 strains of $B$. thuringiensis. (2) Mean of 9 strains of $B$. mycoides. (3) Mean of 10 strains of $B$. cereus. Only two peaks have been used. Circles define $95 \%$ confidence regions for each species.

discrimination. Simple acceptance of the 13-peak solution ignores the fact that the only difference between this and the 2-peak solution is that strain 26 is correctly reallocated. Examination of the pyrograms for this strain indicated that all four replicates showed large heights for peak 10 in comparison to the rest of $B$. mycoides. As the remaining peaks seemed fairly typical for this group we have no explanation for this apparent anomaly. The possibility that this strain was originally misidentified is extremely unlikely as it produced typical B. mycoides colonies (rhizoid growth). In this case it was felt that the 13-peak solution might have been heavily influenced by strain 26 and the 2-peak solution was selected. In the canonical variates plot (Fig. 4) the $95 \%$ confidence regions for B. mycoides and $B$. cereus now overlapped, indicating further that we may expect difficulty in correctly identifying some unknowns from these two groups. The Mahalanobis distances (squared) of each strain from each species mean (Table 2) show that strain 1, although clearly $B$. thuringiensis, is much further from the mean than any other strain of this species. This was caused by large values in peak 19 relative to the other $B$. thuringiensis strains. However, in this case correct allocation will normally be achieved because of the large distance between this species and the other two.

The application of canonical variates analysis to p.g.l.c. data for discrimination between closely related species has been reported previously (O'Donnell, 1978; O'Donnell et al., 1980; O'Donnell \& Norris, 1980). The application of this analysis requires prior knowledge of the taxonomic structure; thus it cannot be used for deriving taxonomies but it is a valuable method for testing them. The introduction of stepwise discriminant analysis and jacknifing takes the process one stage further by enabling a minimal and stable subset of peaks to be selected for use in future discrimination. Reliable estimates of the success rate of such an exercise are available from the jacknifing results. Careful inspection of the Mahalanobis distances may also reveal outliers. 
Table 2. Output from BMDP7M program, showing distances, calculated on a subset of two peaks, of strains from the group means of B. thuringiensis (1), B. mycoides (2) and B. cereus (3)

\begin{tabular}{|c|c|c|c|c|c|}
\hline \multirow[b]{2}{*}{ Organism } & \multirow[b]{2}{*}{$\begin{array}{l}\text { Strain } \\
\text { no. }\end{array}$} & \multicolumn{3}{|c|}{$\begin{array}{c}\text { Jacknifed } \\
\text { Mahalanobis } D^{2}\end{array}$} & \multirow[b]{2}{*}{$\begin{array}{l}\text { Jacknifed } \\
\text { group }\end{array}$} \\
\hline & & 1 & 2 & 3 & \\
\hline B. thuringiensis (1) & $\begin{array}{r}1 \\
2 \\
3 \\
4 \\
5 \\
6 \\
7 \\
8 \\
9 \\
10 \\
11 \\
12 \\
13 \\
14 \\
15 \\
16 \\
17 \\
18\end{array}$ & $\begin{array}{r}19 \cdot 1 \\
0 \cdot 3 \\
0 \cdot 1 \\
0 \cdot 7 \\
0 \cdot 3 \\
0 \cdot 1 \\
1 \cdot 2 \\
0 \cdot 1 \\
0 \cdot 0 \\
0 \cdot 1 \\
0 \cdot 1 \\
0 \cdot 3 \\
1 \cdot 1 \\
0 \cdot 1 \\
0 \cdot 1 \\
0 \cdot 2 \\
1 \cdot 0 \\
0 \cdot 5\end{array}$ & $\begin{array}{l}755 \cdot 0 \\
712 \cdot 3 \\
718 \cdot 5 \\
762 \cdot 0 \\
745 \cdot 0 \\
727 \cdot 7 \\
775 \cdot 6 \\
726 \cdot 2 \\
723 \cdot 5 \\
733 \cdot 2 \\
752 \cdot 0 \\
713 \cdot 6 \\
792 \cdot 0 \\
744 \cdot 2 \\
744 \cdot 2 \\
752 \cdot 8 \\
761 \cdot 5 \\
771 \cdot 9\end{array}$ & $\begin{array}{l}725 \cdot 9 \\
667 \cdot 5 \\
673 \cdot 4 \\
720 \cdot 7 \\
702 \cdot 2 \\
680 \cdot 6 \\
736 \cdot 1 \\
681 \cdot 5 \\
677 \cdot 9 \\
688 \cdot 8 \\
706 \cdot 5 \\
667 \cdot 4 \\
749 \cdot 9 \\
698 \cdot 6 \\
698 \cdot 6 \\
708 \cdot 6 \\
707 \cdot 0 \\
721 \cdot 1\end{array}$ & $\begin{array}{l}1 \\
1 \\
1 \\
1 \\
1 \\
1 \\
1 \\
1 \\
1 \\
1 \\
1 \\
1 \\
1 \\
1 \\
1 \\
1 \\
1 \\
1 \\
1\end{array}$ \\
\hline B. mycoides (2) & $\begin{array}{l}19 \\
20 \\
21 \\
22 \\
23 \\
24 \\
25 \\
26 \\
27\end{array}$ & $\begin{array}{r}1225 \cdot 5 \\
743 \cdot 5 \\
976 \cdot 2 \\
714 \cdot 7 \\
705 \cdot 9 \\
710 \cdot 2 \\
704 \cdot 7 \\
747 \cdot 8 \\
757 \cdot 0\end{array}$ & $\begin{array}{r}15 \cdot 1 \\
0 \cdot 0 \\
7 \cdot 7 \\
12 \cdot 8 \\
3 \cdot 3 \\
1 \cdot 0 \\
4 \cdot 0 \\
29 \cdot 3 \\
1 \cdot 4\end{array}$ & $\begin{array}{r}23 \cdot 1 \\
11 \cdot 7 \\
31 \cdot 9 \\
45 \cdot 4 \\
21 \cdot 4 \\
15 \cdot 1 \\
4 \cdot 4 \\
1 \cdot 2 \\
6 \cdot 8\end{array}$ & $\begin{array}{l}2 \\
2 \\
2 \\
2 \\
2 \\
2 \\
2 \\
3^{*} \\
2\end{array}$ \\
\hline B. cereus (3) & $\begin{array}{l}28 \\
29 \\
30 \\
31 \\
32 \\
33 \\
34 \\
35 \\
36 \\
37\end{array}$ & $\begin{array}{l}721 \cdot 8 \\
756 \cdot 5 \\
720 \cdot 1 \\
715 \cdot 5 \\
754 \cdot 0 \\
662 \cdot 3 \\
660 \cdot 3 \\
662.7 \\
685 \cdot 0 \\
669 \cdot 7\end{array}$ & $\begin{array}{r}11 \cdot 1 \\
10 \cdot 9 \\
5 \cdot 2 \\
8 \cdot 2 \\
7 \cdot 1 \\
15 \cdot 6 \\
22 \cdot 3 \\
16 \cdot 1 \\
14 \cdot 0 \\
10 \cdot 3\end{array}$ & $\begin{array}{l}0.4 \\
1.1 \\
1.5 \\
0.4 \\
1.5 \\
0.8 \\
3.8 \\
0.9 \\
0.2 \\
0.3\end{array}$ & $\begin{array}{l}3 \\
3 \\
3 \\
3 \\
3 \\
3 \\
3 \\
3 \\
3 \\
3\end{array}$ \\
\hline
\end{tabular}

* Strain assigned to the wrong group by selecting minimum jacknifed Mahalanobis $D^{2}$.

\section{REFERENCES}

DIXon, W. J. (1975). Biomedical Computer Programs. Los Angeles: University of California Press.

Lachenbruch, P. A. \& Mickey, M. R. (1968). Estimation of error rates in discriminant analysis. Technometrics 10, 1-11.

MacFie, H. J. H. \& Gutteridge, C. S. (1978). Analysis of pyrolysis gas-liquid chromatography data using multivariate statistical techniques. Journal of Applied Bacteriology 45, iv-v.

MacFie, H. J. H., Gutteridge, C. S. \& Norris, J. R. (1978). Use of canonical variates analysis in differentiation of bacteria by pyrolysis gas-liquid chromatography. Journal of General Microbiology 104, 67-74.

Mahalanobis, P. C. (1936). On the generalised distance in statistics. Proceedings of the National Institute of Sciences of India 2, 49-55.

O'Donnell, A. G. (1978). The application of pyrolysis gas-liquid chromatography to some aerobic sporeformers. Journal of Applied Bacterio$\log y$ 45, v.

O'Donnell, A. G. \& Norris, J. R. (1980). Pyrolysis gas-liquid chromatographic studies in the genus Bacillus. In Classification and Identification of the Aerobic Endospore-forming Bacteria. Edited by R. C. W. Berkeley \& M. Goodfellow. London: Academic Press (in the Press).

O'Donnell, A. G., Norris, J. R., Berkeley, R. C. W., Claus, D., Kaneko, T., Logan, N. A. \& NozAKI, R. (1980). Characterisation of Bacillus 
subtilis, Bacillus pumilus, Bacillus licheniformis and Bacillus amyloliquefaciens by pyrolysis gas-liquid chromatography: characterisation tested using DNA-DNA hybridisation; biochemical tests and API systems. International Journal of Systematic Bacteriology (in the Press).

Oxborrow, G. S., Fields, N. D. \& Puleo, J. R. (1976). Preparation of pure microbiological samples for pyrolysis gas-liquid chromatography studies. Applied and Environmental Microbiology 32, 306-309.

Oxborrow, G. S., Fields, N. D. \& Puleo, J. R. (1977a). Pyrolysis gas-liquid chromatography studies of the genus Bacillus. Effect of growth time on pyrochromatogram reproducibility. In Analytical Pyrolysis, pp. 69-76. Edited by C. E. R.
Jones \& C. A. Cramers. Amsterdam: Elsevier Scientific Publishing Co.

Oxborrow, G. S., Fields, N. D. \& Puleo, J. R. $(1977 b)$. Pyrolysis gas-liquid chromatography of the genus Bacillus: effect of growth media on pyrochromatogram reproducibility. Applied and Environmental Microbiology 33, 865-870.

ReINER, E. \& BAYER, F. L. (1978). Botulism: a pyrolysis gas-liquid chromatographic study. Journal of Chromatographic Science 16, 623-629.

Stack, M. V., Donoghue, H. D., TYler, J. E. \& Marshall, M. (1977). Comparison of oral streptococci by pyrolysis gas-liquid chromatography. In Analytical Pyrolysis, pp. 57-68. Edited by C. E. R. Jones \& C. A. Cramers. Amsterdam: Elsevier Scientific Publishing Co. 